University of San Diego

Digital USD

Spring 5-20-2020

\title{
The Relationship Between Undergraduate Gender, Drinking Motives, Alcohol Involvement, and Neuroticism
}

Jaymi Wilson

University of San Diego

Follow this and additional works at: https://digital.sandiego.edu/honors_theses

Part of the Psychology Commons

\section{Digital USD Citation}

Wilson, Jaymi, "The Relationship Between Undergraduate Gender, Drinking Motives, Alcohol Involvement, and Neuroticism" (2020). Undergraduate Honors Theses. 66.

https://digital.sandiego.edu/honors_theses/66

This Undergraduate Honors Thesis is brought to you for free and open access by the Theses and Dissertations at Digital USD. It has been accepted for inclusion in Undergraduate Honors Theses by an authorized administrator of Digital USD. For more information, please contact digital@sandiego.edu. 
The Relationship Between Undergraduate Gender, Drinking Motives, Alcohol Involvement, and Neuroticism

$\longrightarrow$

\author{
A Thesis \\ Presented to \\ The Faculty and the Honors Program \\ Of the University of San Diego
}

By

Jaymi Michelle Wilson

Psychological Sciences

2020 
The Relationship Between Undergraduate Gender, Drinking Motives, Alcohol Involvement, and Neuroticism

Jaymi Wilson

University of San Diego 


\begin{abstract}
The onset of problem drinking behaviors for many college undergraduates occurs as they enter a new environment devoid of previous inhibiting factors. For whatever reasons college students choose to drink — and not all of them do - it is imperative to understand both the motives and influences affecting increased alcohol related risks. After conducting a thorough literature review, I propose a research design to test the hypothesis that drinking motives and alcohol involvement are mediated by neuroticism. To support this prediction, I will present a model that considers the impact that subject personality, namely neuroticism, may have in mediating the relationship. Specifically, this differential impact of neuroticism is a product of females' higher probability to use drinking behavior as a coping mechanism. Further, I hypothesize that males are less likely to report drinking for emotional reasons and as such are less likely to present the mediated effect. Finally, I discuss the limitations inherent to undergraduate survey research on a sensitive topic. This study provides insight into differences in drinking motives that may generate new approaches to alcohol education for college undergraduates.

Keywords: drinking motives, undergraduates, gender, neuroticism, personality, alcohol involvement
\end{abstract}


GENDER, DRINKING MOTIVES, ALCOHOL INVOLVEMENT, AND NEUROTICISM

The Relationship Between Undergraduate Gender, Drinking Motives, Alcohol Involvement, and Neuroticism

Alcohol is the third leading preventable cause of death in the United States with an estimated 88,000 people dying from alcohol related causes annually (Alcohol Facts and Statistics, 2020). According to the 2018 National Survey on Drug Use and Health (NSDUH), 14.4 million adults ages 18 and older had Alcohol Use Disorder (AUD) (Alcohol Facts and Statistics, 2020). Given that college marks a time period where young adults face increased risk for initiation and continuation of problem drinking behaviors and the younger the age of drinking onset, the greater the chance that an individual will develop an alcohol disorder, it is of the utmost importance to conduct research to help better understand patterns of undergraduate drinking (Ichiyama et al., 2018; Age of Drinking Onset, 1998).

Although the majority of U.S. college undergraduates are under the legal drinking age of 21, periods of heavy alcohol consumption are most often reported between the ages of 18-21 (Chen \& Kandel, 1995). In fact, according to a national survey, almost 55\% of college students ages 18-22 drank alcohol in the past month, and 1 in 3 of them engaged in binge-drinking during that timeframe (College Drinking, 2020). Whether an undergraduate chooses to drink - and not all of them do - there are certain aspects of college life, such as less structured schedules, widespread availability of alcohol, stress associated with the transition to college, and limited interactions with parents, that can lead to increased risk for inappropriate alcohol use (College Drinking, 2020). Factors related to specific college environments also are significant in predicting high alcohol consumption, including Greek life and housing accommodation. For example, students attending universities with very active Greek life and with prominent athletic programs tend to drink more than students at other universities (College Drinking, 2020). 
GENDER, DRINKING MOTIVES, ALCOHOL INVOLVEMENT, AND NEUROTICISM

Similarly, alcohol consumption is highest among students living in fraternity and sorority houses and lowest among students who live with their families and commute to campus (College Drinking, 2020).

\section{Drinking Motives}

Alcohol behaviors are driven by a variety of factors, and motivations for drinking have been shown to play a significant role in undergraduate alcohol consumption (Cooper, 1994). Cooper (1994) identified four primary motives for drinking: 1) enhancement; 2) social; 3) conformity; and 4) coping. Enhancement motives refer to drinking for an increased positive experience or drinking to do the otherwise impossible (e.g. drinking because it makes an experience more exciting). Social motives refer to drinking to enjoy social situations or drinking to be more sociable (e.g. drinking because you are at a party). Conformity motives refer to drinking to combat explicit or implicit pressures to do so (e.g. your friends pressure you to drink with them). Coping motives refer to drinking to escape negative emotions or experiences (e.g. drinking to forget problems). There is evidence that these drinking motives result in different drinking outcomes. For example, those who report drinking to cope are more likely to show signs of alcohol-related problems, while those who report drinking for enhancement are more likely to partake in heavy episodic drinking (Cooper, 1994).

Undergraduates consistently report enhancement and social motives as primary reasons to drink over conformity and coping motives, and these are often linked with higher drinking levels (Kuntsche et al., 2005). Though less frequently reported by undergraduates, coping and conformity motives are more strongly associated with negative alcohol-related consequences than enhancement and social motives (Kuntsche et al., 2005). This relationship can be explained by differences in end-state goals; in other words, coping and conformity motives are internally 
directed and utilized to regulate a negative state such as anxiety or discomfort and as such are more likely to yield negative alcohol-related consequences, while enhancement and social motives are often utilized to regulate the external experience of an individual and as such are likely to lead to higher levels of alcohol consumption but not necessarily alcohol-related problems. Furthermore, drinking motives are observed differentially across gender, with female adolescents reporting negative affect or depressed mood as a reason to drink more than males, who are more likely to report "drinking to feel high" as a primary motive (Harrell \& Karem, 2008). This variation in drinking motive by gender provides meaningful insight into what causes differentiated drinking outcomes for male and female students.

\section{Gender}

Research has consistently shown that adult males consume more alcohol and experience more alcohol-related problems than adult females (Substance Abuse and Mental Health Services Administration, 2008). For example, the Substance Abuse and Mental Health Services Administration's (SAMHSA) National Survey on Drug Use and Health (NSDUH) indicates that $7.6 \%$ of adult men have AUD while it impacts only $4.1 \%$ of adult women (Alcohol Facts and Statistics, 2020). Similarly, the 2008 NSDUH indicated that approximately $65.3 \%$ of men ages 18-25 reported some current alcohol use compared to $57.1 \%$ of women in the same age group (SAMHSA, 2008). It is hypothesized that men drink more than women in part because of social norms and gender roles that encourage them to do so (Schulte et al.,2009). For example, Landrine, Bardwell, and Dean (1988) found that attitudes and expectations of drinking and drunkenness were influenced by adherence to traditional gender roles. Social norms and gender roles often link masculinity to drinking and intoxication, so males are more likely to partake in heavier drinking behaviors. Inversely, stereotypical female characteristics like virtue and 
GENDER, DRINKING MOTIVES, ALCOHOL INVOLVEMENT, AND NEUROTICISM

emotionality are not associated with alcohol use and as such women are less likely to report increased levels of alcohol involvement (Ricciardelli, Connor, Williams, \& Young, 2001). Given established gender differences in drinking prevalence (e.g. men drink more than women) and motive (e.g. women are more likely to report drinking when in a bad mood), it stands to reason that neuroticism may play an important role in understanding the relationship between gender, drinking motives, and alcohol involvement.

\section{Neuroticism}

Defined as a tendency towards negative affect including anxiety, moodiness, worry, fear, anger, depressed mood, and more, neuroticism can play a large role in shaping behavioral outcomes for undergraduate students during the naturally anxiety-inducing transition into college. Given that drinking prevalence and motives vary by gender, neuroticism is worth considering as it is likely to have covariance with coping drinking motive. Foster and colleagues (2014) found that increased depressed mood or depressive symptoms are positively associated with drinking regardless of gender. As such, it stands to reason that individuals who experience higher base levels of negative affect (e.g. neuroticism) might drink more than those who are lower in negative affect, and this relationship would be exacerbated by the presence of coping drinking motive as those with higher negative affect would have greater motivation to drink to relieve unpleasant emotional states, like depressed mood.

Furthermore, the paradigm shift from childhood into adulthood marked by the onset of the undergraduate experience can be a large stressor for adolescents (Temmen \& Crocket, 2020). The stress associated with the challenges of early adulthood and the transition to a new stage of life may help explain high levels of alcohol involvement during this time. Stress is the body's natural response to challenge or demand and is often accompanied by emotional or physical 
tension, which in turn leads to attempts to regulate these unpleasant feelings (Sher and Grekin 2007). If an undergraduate is particularly high in neuroticism, they are likely to be sensitive to this newfound stress in ways other undergraduates may not be and it is possible this individual may choose to drink as a means of reducing their tension or attempting to regulate their emotional state. Jorm (1987) established that females report higher base rates of neuroticism than males. The difference in rates of neuroticism among males and females was greater in young and middle-aged adults than in children or the elderly, leading to the assumption that neuroticism has greater effects during the middle of one's life but minimal impact at the extremes of young or old age (Jorm, 1987). This is especially relevant to the study of neuroticism in relation to problem drinking behaviors in undergraduates because the undergraduate years fall into the age range more seriously impacted by neuroticism, and as such it is likely that neuroticism could impact drinking behavior. Thus, it is of interest to researchers to consider neuroticism as a potential predictor for undergraduate alcohol consumption.

\section{The Proposed Study}

The proposed study aspires to address a gap in the literature by evaluating the relationship between undergraduate alcohol involvement by considering the interaction between drinking motives, gender, and neuroticism. Based on previous research, I expect correlations and main effects such that: neuroticism will produce a mediated effect for female undergraduates such that there will be a positive association between coping drinking motive and alcohol involvement when neuroticism is high; there will be a direct, positive association between enhancement drinking motive and alcohol involvement for males; and males will report consuming more alcohol than females. I also predict secondary effects such that drinking motive social will have the highest correlation with alcohol involvement regardless of neuroticism. 
Because individuals with higher levels of neuroticism are likely to have more occasion to use alcohol to cope with negative affect compared to individuals lower in neuroticism, I hypothesize that female undergraduates will produce the mediated effect due to the higher base rate of neuroticism present in females. Furthermore, due to prior research that suggests women report higher coping drinking motive and neuroticism than men while men report higher enhancement drinking motive, I expect that men will not produce the mediated effect due to the likelihood that males will preferentially report enhancement or social motives as primary motives to conform to masculine gender norms (Landrine et al., 1988).

\section{Methods}

\section{Participants}

The sample will consist of 150 undergraduate students at the Undergraduate University of San Diego and San Diego State University. Participants will be recruited via in-class recruitment and flyers posted around the university campuses and will participate for experimental credit in an undergraduate psychology course.

\section{Procedure}

Participants will complete an online survey instrument that consists of 50 questions and will take approximately 10-15 minutes to complete. Participants will give their informed consent prior to completing the survey and be given an option to get class research credits in exchange for their participation. The project upon which this study was based received approval from the Institutional Review Board of the University of San Diego prior to its implementation.

\section{Measures}

Measures used in the present study included a set of self-report items that examined alcohol involvement (a summary measure of alcohol related problems, binge drinking frequency 
in the past two weeks, and frequency of being drunk in the past 30 days), neuroticism from the NEO Personality Inventory, and the drinking motives scale. Demographic information such as year in school, racial background, ethnicity, age, Greek life affiliation, and gender are also collected. Internal consistency reliability will be estimated using Cronbach's Alpha for each scale.

\section{Alcohol Involvement}

The composite alcohol involvement index is computed by standardizing and then summing three alcohol related measures. The alcohol-related problems measure (ARP) is a 17item scale that examines participants' negative experiences over the past three months due to drinking. Responses range from Yes/No and 1-2 times to 10 or more. Binge drinking frequency measures the number of times students consumed 5 or more drinks ( 4 for women) over the past two weeks in a single two-hour period. The drunk in the past 30 days measure asks students the number of times they have been drunk in the past month (30 days) on a scale of 0 to 15 times or more. Because ARP is a summed measure consisting of multiple items, I calculated an internal consistency reliability estimate for the ARP measure (Alpha=.67).

\section{Neuroticism}

The Neuroticism subscale from the NEO Five-Factor Personality Inventory consists of 12 items. Items assess an individual's tendency towards negative affect by asking participants to rate their agreement with statements like "I am not a worrier" and "I often feel inferior to others.” Responses range from 1 (Strongly Disagree) to 5 (Strongly Agree). The internal consistency reliability estimate for the Neuroticism subscale is .74.

\section{Drinking Motives}


The Drinking Motives Questionnaire-Revised (DMQR; Cooper, 1994) will be used to evaluate drinking motives. Participants provide ratings on a five-point Likert scale ranging from 1 (Never/Almost Never) to 5 (Almost Always/Always) regarding 20 reasons why they might be motivated to drink(e.g., "To forget your worries" for coping drinking motive and "To feel high" for enhancement and so on). The measure yields four subscales, one for each of the four drinking motives.

\section{Analyses}

Mediated path models based on multiple regression are estimated using the statistical program known as AMOS (analysis of moment structures). Two path models will be estimated by gender. Each path model estimates the direct effects of drinking motives on alcohol involvement and the indirect effects of drinking motives on alcohol involvement mediated by neuroticism.

\section{Proposed Relationships}

Figure 1 shows the proposed mediated relationships and the main effects hypothesized.

Figure 1. Proposed Mediated Path Model

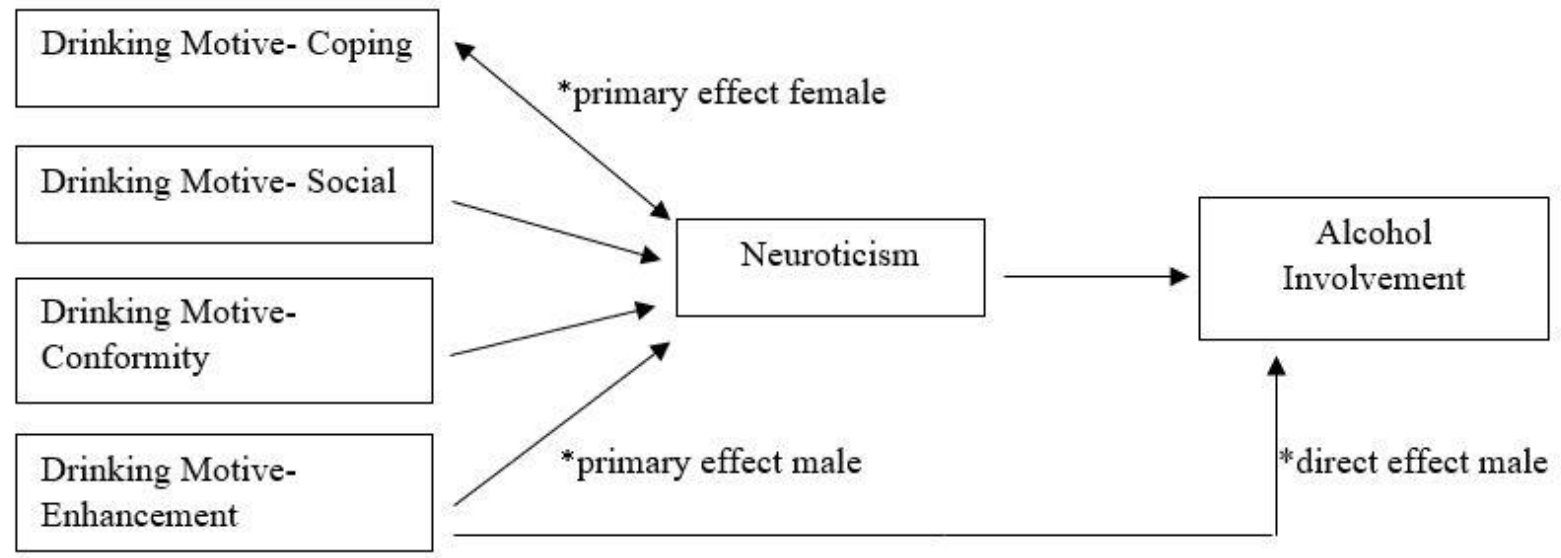

Note. Model would be analyzed separately by gender.

Note. Secondary effects for males and females are predicted for Drinking Motive- Social. 


\section{Discussion}

The present study extends previous research evaluating undergraduate drinking motives, alcohol involvement, and neuroticism by considering the potential mediated relationship between coping drinking motive, gender, and neuroticism. Predictions are consistent with the literature, proposing that females will report higher levels of neuroticism and as such have more tendencies to report coping drinking motive as a means of alcohol involvement. Although males will have higher overall rates of alcohol involvement, neuroticism will have higher covariance with alcohol involvement for females because they are more likely to drink for relief from negative moods. As previously discussed, one reason for this may be the differences in gender norms and socialization between males and females. Given that females face greater stigma surrounding alcohol consumption, it follows that the mediated impact of neuroticism in the female path model is a product of females' higher probability to use drinking as a coping mechanism.

Because females are more likely to be sensitive to their emotions given the stereotypes surrounding feminine expression, it has also been noted that females may be more likely to drink in response to problems in romantic and other personal relationships while males may be more likely to do so in response to work-related stressors (Temmen \& Crocket, 2020). These results build on and support prior research showing that traditional gender roles can influence the relationship between stressors and alcohol use.

Also in line with previous research is the prediction that males will report enhancement drinking motive as their predominant motive. Due to societal standards more accepting of male alcohol consumption, males will be less likely to report drinking for emotional reasons and as such are less likely to present the mediated effect predicted in the female sample. Similarly, the direct effect between enhancement drinking motive and alcohol involvement reflects positive 
GENDER, DRINKING MOTIVES, ALCOHOL INVOLVEMENT, AND NEUROTICISM

drinking expectations present in non-neurotic men. It is likely that non-neurotic men expect enhancement to positively impact their alcohol experience due to societal cues that normalize and glorify male drinking behaviors. One contributing factor to this male socialization may be a difference in parental monitoring among males and females. Research has found that there is a clear relationship between parental monitoring behavior and female alcohol use that suggests monitoring may be a strong protective factor for females, which is likely because cultural norms dictate a double standard for the monitoring and punishment of deviance for girls and boys (Schulte et al., 2009). The discrepancy in treatment between genders serves as a protective factor against risk-taking for female adolescents who are told to be weary of the consequences of such actions, whereas males are often given more freedom and encouragement to engage with peers in ways deemed inappropriate for females. Thus, males are more likely to engage in heavy drinking among their male peers to enhance their social experiences more so than their female counterparts.

\section{Limitations and future directions}

On sensitive topics such as alcohol consumption, self-reported survey data is subject to considerable participant bias and thus may be less objective than other data collection methods. Further, there may be significant report bias across gender as males and females differentially report their alcohol involvement and neuroticism. Due to stigma surrounding female drinking and male expression of emotion, it is likely self-preservation biases will arise in such data. Despite the limitations, this study provides meaningful insight into the difference between males and females in drinking motives and outcomes. This insight will aid in generating new approaches to alcohol education for college undergraduates and provide a means for administration to develop student-centered approaches that address male and female needs 
separately. Furthermore, these findings may be beneficial in helping college undergraduates better understand the risks associated not only with their gender, but also with other facets of their identity that influence alcohol involvement, like personality traits and self-selected peer groups. Overall, this research expands the body of literature addressing issues of alcohol involvement on undergraduate campuses and provides insight into future sex-driven educational models to pursue in combatting alcohol misuse on college campuses around the United States. This research does not encompass all issues related to alcohol use in undergraduates, and as such more research on the impact of gender on drinking motives and personality trait interactions is needed. 


\section{References}

Age of Drinking Onset Predicts Future Alcohol Abuse and Dependence. (1998, January 14). Retrieved May 8, 2020, from https://www.niaaa.nih.gov/news-events/news-releases/agedrinking-onset-predicts-future-alcohol-abuse-and-dependence

Alcohol Facts and Statistics. (2020, February 18). Retrieved May 8, 2020, from https://www.niaaa.nih.gov/publications/brochures-and-fact-sheets/alcohol-facts-and-statistics

Chen, K., \& Kandel, D. B. (1995). The natural history of drug use from adolescence to the midthirties in a general population sample. American Journal of Public Health, 85(1), 41-47. doi: 10.2105/ajph.85.1.41

College Drinking. (2020, February 10). Retrieved May 8, 2020, from https://www.niaaa.nih.gov/publications/brochures-and-fact-sheets/college-drinking

Cooper ML. (1994). Motivations for alcohol use among adolescents: Development and validation of a four-factor model. Psychological Assessment, 6:117-128.

Foster, D. W., Young, C. M., Steers, M.-L. N., Quist, M. C., Bryan, J. L., \& Neighbors, C. (2014). Tears in Your Beer: Gender Differences in Coping Drinking Motives, Depressive Symptoms and Drinking. International Journal of Mental Health and Addiction, 12(6), 730-746. doi: 10.1007/s11469-014-9504-3

Harrell, Z. A. T., \& Karim, N. M. (2008). Is gender relevant only for problem alcohol behaviors? An examination of correlates of alcohol use among college students. Addictive Behaviors, 33(2), 359-365. https://doi.org/10.1016/j.addbeh.2007.09.014

Ichiyama, M., Wescott, A., Swart, K., Birch, K., \& Harrison, S. (2018). Developmental transitions and college student drinking: Why parents still matter. In H.E. Fitzgerald \& L.I.

Jorm, A. F. (1987). Sex Differences in Neuroticism: A Quantitative Synthesis of Published Research. Australian \& New Zealand Journal of Psychiatry, 21(4), 501-506. doi: $10.3109 / 00048678709158917$

Kuntsche E, Knibbe R, Gmel G, Engels R. (2005). Why do young people drink? A review of drinking motives. Clinical Psychology Review, 25(7):841-861.

Landrine H, Bardwell S, Dean T. (1998). Gender expectations for alcohol use: A study of the significance of the masculine role. Sex Roles, 19:703-712.

Ricciardelli LA, Connor JP, Williams RJ, Young RM. (2001). Gender stereotypes and drinking cognitions as indicators of moderate and high risk drinking among young women and men. Drug and Alcohol Dependence, 61:129-136.

Schulte, M. T., Ramo, D., \& Brown, S. A. (2009). Gender differences in factors influencing alcohol use and drinking progression among adolescents. Clinical Psychology Review, 29(6), 535-547. doi: 10.1016/j.cpr.2009.06.003 
Sher, K., \& Grekin, E. R. (2007). Alcohol and affect regulation. In J. J. Gross (Ed.), Handbook of emotion regulation (pp. 560-580). New York, NY: Guilford.

Substance Abuse and Mental Health Services Administration, Office of Applied Studies. Results from the 2007 National Survey on Drug Use and Health: National Findings. Rockville, MD: 2008. (NSDUH Series H-34, DHHS Publication No. SMA 08-4343).

Temmen, C.D., Crockett, L.J. (2020). Relations of Stress and Drinking Motives to Young Adult Alcohol Misuse: Variations by Gender. J Youth Adolescence, 49, 907-920. https://doi.org/10.1007/s10964-019-01144-6 